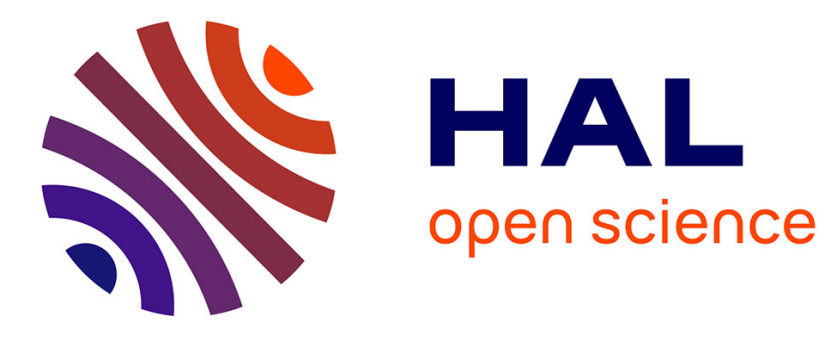

\title{
Using an Artificial Financial Market for Assessing the Impact of Tobin-like Transaction Taxes
}

\author{
Katiuscia Mannaro, Michele Marchesi, Alessio Setzu
}

\section{To cite this version:}

Katiuscia Mannaro, Michele Marchesi, Alessio Setzu. Using an Artificial Financial Market for Assessing the Impact of Tobin-like Transaction Taxes. Journal of Economic Behavior and Organization, 2008, 67 (2), pp.445. 10.1016/j.jebo.2006.10.011 . hal-00601885

\section{HAL Id: hal-00601885 \\ https://hal.science/hal-00601885}

Submitted on 21 Jun 2011

HAL is a multi-disciplinary open access archive for the deposit and dissemination of scientific research documents, whether they are published or not. The documents may come from teaching and research institutions in France or abroad, or from public or private research centers.
L'archive ouverte pluridisciplinaire HAL, est destinée au dépôt et à la diffusion de documents scientifiques de niveau recherche, publiés ou non, émanant des établissements d'enseignement et de recherche français ou étrangers, des laboratoires publics ou privés. 


\section{Accepted Manuscript}

Title: Using an Artificial Financial Market for Assessing the Impact of Tobin-like Transaction Taxes

Authors: Katiuscia Mannaro, Michele Marchesi, Alessio Setzu

PII: $\quad$ S0167-2681(08)00093-0

DOI: $\quad$ doi:10.1016/j.jebo.2006.10.011

Reference: $\quad$ JEBO 2204

To appear in: Journal of Economic Behavior \& Organization

Received date: 3-11-2005

Revised date: $\quad 31-5-2006$

Accepted date: $\quad$ 5-10-2006

Please cite this article as: Mannaro, K., Marchesi, M., Setzu, A., Using an Artificial Financial Market for Assessing the Impact of Tobin-like Transaction Taxes, Journal of Economic Behavior and Organization (2007), doi:10.1016/j.jebo.2006.10.011

This is a PDF file of an unedited manuscript that has been accepted for publication. As a service to our customers we are providing this early version of the manuscript. The manuscript will undergo copyediting, typesetting, and review of the resulting proof before it is published in its final form. Please note that during the production process errors may be discovered which could affect the content, and all legal disclaimers that apply to the journal pertain. 


\title{
Using an Artificial Financial Market for Assessing the Impact of Tobin-like Transaction Taxes
}

\author{
Katiuscia Mannaro, Michele Marchesi*, Alessio Setzu \\ DIEE, University of Cagliari
}

\begin{abstract}
The Tobin Tax is a solution proposed by many economists for limiting the speculation in foreign exchange and stock markets and for making these markets stabler. In this paper we present a study on the effects of a transaction tax on one and on two related markets, using an artificial financial market based on heterogeneous agents.

The microstructure of the market is composed of four kinds of traders: random traders, fundamentalists, momentum traders, and contrarians, and the resources allocated to them are limited. In each market it is possible to levy a transaction tax. In the case of two markets, each trader can choose in which market to trade, and an attraction function is defined that drives their choice based on perceived profitability. We performed extensive simulations and found that the tax actually increases volatility and decreases trading volumes. These findings are discussed in the paper.
\end{abstract}

\section{Introduction}

The deep financial crises over the past decade, starting with the Mexican pesos crisis in 1994 to the one in Argentina in 2001, raised serious doubts as to the ability of free markets to reflect the "true" value of a specific currency. In fact, too many speculative activities can produce a strong bias in exchange rates and create a monetary crisis, or at least amplify its effects. Many observers claim that a tax on currency transactions may prove a powerful tool for penalizing speculators and stabilizing markets. For these reasons, in recent years there has been an ongoing interest in the idea advanced by some economists (the most

* Corresponding author. Tel.: +39070 675 5757; fax: +39070675 5782.

Email address: michele@diee.unica.it (Michele Marchesi). 
famous being James Tobin; see Tobin 1978) to levy a small tax on currency transactions.

Over the last thirty years the volume of foreign exchange trading has increased hugely. In 1973, daily trading volume averaged around $\$ 15$ billion; today, it averages $\$ 1.9$ trillion (Galati et al. 2005). Moreover, $90 \%$ of the trading volume concerns short-term transactions. In general, economists believe that most short-term transactions are of a speculative nature, and many considered them to be a source of market volatility and instability. Instead, medium or long term transactions are usually related to real investments.

In 1936, Keynes in The General Theory of Employment, Interest, and Money asserted that the levy of a small tax on all stock exchange transactions should contribute to reducing instability in domestic stock markets. According to Keynes, this tax should discourage speculators from trading, resulting in lower price volatility of the taxed asset.

In 1978, the Nobel Prize Laureate in Economics James Tobin proposed the levy of a small tax $(0.1 \%)$ on all foreign exchange transactions. This would penalize short-term speculators but not long-term investors, favoring market stability. Later, several authors (see, e.g. Palley 1999, Baker 2000, Felix and Sau 1996, Jeffrey A. 1996, Kupiec 1995) proposed a similar solution for other kinds of securities.

On the other hand, some economists disagree with Keynes and Tobin's views. Friedman (1953) challenged these theories, arguing that speculative trading could stabilize prices.

Only a few empirical analyses have studied the effects of transaction taxes on price volatility. Umlauf (1993) studied Swedish stock market data and showed that the introduction of a Swedish tax increased the volatility of stock prices. It is worth noting that the tax level was set at $1 \%$ in 1984 and at $2 \%$ in 1986: such values are far too high compared with the percentage proposed by Tobin.

Habermeier and Kirilenko (2003) analysed the effects of transaction costs and of capital controls on markets and showed that they can have negative effects on price discovery, volatility, and liquidity, reducing market efficiency. They produced evidence that the Tobin tax increases market volatility by discouraging transacting, thereby reducing market liquidity.

Palley (2003) argues that the Tobin tax is good for financial stability, and that total transaction costs are not necessarily increased by its imposition. Actually, transaction costs could change the composition of traders, precluding short-term investors from the market. It leads to a reduction in volatility and consequently in total transaction costs. 
Aliber et al. (2003) demonstrated that a Tobin tax on Foreign Exchange Transactions may increase volatility. They constructed the time series of monthly transaction costs estimates, volatility, and volume for four currencies (the British Pound, the Deutsche Mark, the Japanese Yen and the Swiss Franc) for the period 1977 to 1999, and showed that volatility is positively correlated with the level of transaction costs, while trading volume is negatively correlated. Their results suggest that an increase in transaction costs leads to a decrease in trading volume. Therefore, the effect of the tax on volatility is exactly the opposite of what the proponents of the Tobin tax would like to have seen. On the other hand, their findings were strongly criticized by Werner (2003), who argued that the direction of causality between tax and volatility/volumes may be just the opposite.

In The effectiveness of Keynes-Tobin transaction taxes when heterogeneous agents can trade in different markets: a behavioral finance approach, Westerhoff and Dieci (2006) developed a model in which rational agents apply technical and fundamental analyses for trading in two different markets. Their model shows that if a transaction tax is imposed on one market, speculators leave this market, making it less volatile. Therefore, their model confirms Tobin's hypothesis.

Thus, the debate on whether levying a small tax on each market transaction could help to reduce speculation and price volatility is still open. The reactions of stock markets to the imposition of margin requirements and of short-selling restrictions are still not fully understood, and rules and regulations could be implemented without a clear understanding of their potential impact. It is difficult to test the effects of restrictions on real markets empirically, and the simulation approach could help us to understand these phenomena in a noninvasive way.

In this paper, we contribute to this debate by proposing a multi-agent model for analyzing the effects of introducing a transaction tax on one and then on two related stock markets from a structural and behavioral perspective. Our aim is to study if and how market volatility and trading mechanism are influenced by a Tobin tax, and if and how traders change their strategies. Our model is agent-based, and only one asset is negotiated in each market. We developed a simulator acting as an artificial financial market. This computational-experimental approach enabled us to perform several tests and to validate some hypotheses.

The microstructure of the market model is composed of four kinds of traders (Raberto et al. 2003):

- Random traders, who trade at random;

- Fundamentalists, who pursue the "fundamental" value; 
- Chartists, trend-followers who are divided into

- Momentum traders, who follow the market trend; and

- Contrarian traders, who follow the opposite of the market trend.

Each trader is modeled as an autonomous agent, with a limited stock portfolio and cash. No trader can issue orders exceeding the finiteness of the resources available to him. The pricing mechanism of each asset is based on the intersection of the demand-supply curves.

In the case of two stock markets, at each simulation step the trader decides in which market to operate by evaluating an attraction function for both markets and deciding accordingly.

In particular we studied the dynamics of a single market. When the tax was not applied in a closed market, we obtained the same results as reported in Raberto et al. (2003), with fundamentalist and contrarian traders gaining wealth at the expense of momentum traders and, to a lesser extent, of random traders. We modeled the levy of a transaction tax as a cash draining on each transaction. These findings are the focal point of our paper.

We then examined market dynamics and traders' behavior for two stock markets. First we studied the markets with no tax levied, and then the effects of introducing the tax in one market.

We are neither advocates nor opponents of the Tobin tax, but as researchers we look upon the tax simply as a specific measure proposed to achieve a particular economic objective. Our aim is consequently to study whether the introduction of the Tobin tax can stabilize financial markets or not. Levying the tax on one market enabled us to analyze a number of issues, for example whether the taxed market becomes stabler (i.e., volatility in a taxed market is attenuated).

The paper is organized as follows. In Section 2 we present the market model, including traders' behavior, and the price-clearing mechanism. In the subsections of Section 3 we present the results achieved with a single market, and with the interplay of two markets under various tax conditions.

\section{Method and Model}

In the proposed model, we consider an economy with two stock markets, each trading an asset with similar characteristics, and analyze prices dynamics and traders' behavior.

The model includes both structural and behavioral assumptions. By structural 
assumptions we intend those trading mechanisms that define the market rules, while behavioral assumptions refer to trading strategies and the rules used by traders for making their decisions (see LiCalzi and Pellizzari 2002). Each trader is modeled as an autonomous agent, and each is given a certain amount of cash and assets. The simulator ${ }^{1}$ enables us to track the traders' portfolio, the price series history and the orders issued by each trader for each time step. A time step is conventionally one day in duration.

First we examined the dynamics of a single market, both without and with a transaction tax of $0.05 \%$ to $0.5 \%$. Then we considered the case of two markets, examining market trends without tax, and then the effects of introducing the tax first in one market and, lastly, in both markets.

At each time step, corresponding roughly to one trading day, each trader trades only within one market. Before trading takes place, each trader, in accordance with an attraction function based on expected gain, may decide to leave one market, switching to the other.

The trader model defines the basic behavioral rules for each kind of trader. Each kind of trader is tuned to the values of some parameters in such a way that the resulting price series show the well-known "styilized facts", and price volatility is similar to that found in real markets. Each kind of trader is provided with an "activity" parameter that roughly controls the activity of the trader and her/his reactivity to the markets, thus influencing the trader's contribution to price volatility. After many trials, we were able to introduce a parameter $k$ common to all kinds of traders, an increase in $k$ leads to an increase in volatility and in volumes.

We concentrated our study on the effects of different compositions of the populations behavior on taxed (and non-taxed) markets. The price clearing mechanism we used is the same in all simulations and is "neutral" under this respect. Other works analyzed market dynamics using different market mechanisms and different trade behavioral rules in terms of stylized facts and of allocative efficiency (see, e.g., Bottazzi et al. 2005).

We studied the case of a single market to assess the impact of a transaction tax on price volatility and traders' wealth. Then, we studied two related stock

${ }^{1}$ Our market simulation software has been developed using the GASM (Genoa Artificial Stock Market; see Raberto et al. 2001) core. Since one of the ultimate goals of our work is to develop a general framework for financial market simulation, we have re-engineered the original GASM in order to extend its features and to adapt it to our needs.

The model follows an object-oriented approach, and has been implemented in Smalltalk language, following XP (Extreme Programming) software development practices (Beck and Andres 2004). 
markets to assess the impact of levying a tax on one of them, and then on both.

\subsection{Traders' behavior}

The proposed model includes $N$ traders having four different kinds of behavior: random, fundamentalist, momentum and contrarian. At each simulation step, a trader can issue orders with a given probability, which we usually set at $10 \%$ for every trader. In the case of two markets, each trader chooses the most attractive market, according to her/his attraction function.

\subsubsection{Random traders}

Random traders (type R) are characterized by the simplest trading strategy. They are traders with zero intelligence and issue random orders. Random traders represent the bulk of traders who trade for reasons associated with their needs and not with market behavior.

If a random trader decides to issue an order, it may be a buy or sell order with equal probability. The order amount is computed at random, but cannot exceed the trader's actual cash and stock availability. The limit price $\left(l_{i}^{b}\right)$ of a buy order is computed multiplying the current price by a random number drawn from a Gaussian distribution $N\left(\mu, s_{i}\right)$, as shown in equation 1a.

$$
\begin{aligned}
& l_{i}^{b}=p(t) \cdot N\left(\mu, s_{i}\right) \\
& l_{i}^{s}=p(t) / N\left(\mu, s_{i}\right) .
\end{aligned}
$$

The mean $\mu$ is set at a value equal to 1.01 in order to have a spread between the limit prices of sell/buy orders (Raberto et al. 2003). The standard deviation of this distribution, $s_{i}$, depends on the historical market standard deviation, $\sigma_{i}\left(\tau_{i}\right)$, computed on a past price series whose length $\left(\tau_{i}\right)$ depends on each trader, according to equation 2 :

$$
s_{i}=k * \sigma_{i}\left(\tau_{i}\right)
$$

The limit price $\left(l_{i}^{s}\right)$ of a sell order is computed fairly symmetrically as shown in equation $1 b$.

We set the window length $\tau_{i}$ used for random traders to a value randomly chosen for each trader between 2 and 5 , while the value of $k$ was set at 1.9. These values differ somewhat from those typically used in past simulations 
with the same model (Raberto et al. 2001) that had a longer time window (3-20) and a lower value of $k$ (about 1.1). By so doing, we increased the feedback of price volatility on trader's behavior. In this way, we obtained more realistic price statistical behavior in term of stylized facts, varying the trader population and levying various tax percentages.

\subsubsection{Fundamentalist traders}

Fundamentalists (type F) strongly believe that each asset has got a fundamental price $\left(p_{f}\right)$ related to factors external to the market and, sooner or later, the price will revert to that fundamental value. The fundamental price is the same for all fundamentalists. If a fundamentalist decides to trade, s/he places a buy (sell) order if the last price $p(t-1)$ is lower (higher) than the fundamental price $p_{f}$. Fundamentalists' order limits are set toward $p_{f}$, and their size (in stocks for sell orders and in cash for buy orders) equals a fraction of the current amount of stocks or cash owned by the trader. This size is proportional to a term $q$ shown in equation 3 , where $k$ is the same $k$ used for random traders in equation 2.

$$
q=k \cdot \frac{\left|p(t)-p_{f}\right|}{p_{f}}
$$

When a transaction tax is levied, these computations are performed increasing (or decreasing) the current price of the tax value.

\subsubsection{Momentum traders}

Momentum traders (type M) are trend-followers. They play the market following past price trends and rely strictly on price information. Momentum traders buy (sell) when the price goes up (down). They represent, in a simplified way, traders following technical analysis rules and traders following a herd behavior. A time window $\left(\tau_{i}\right)$ is assigned to each momentum trader at the beginning of the simulation through a random draw from a uniform distribution of integers in the range 2 to 10 days.

If the momentum trader issues a buy (sell) order, the limit price $l_{i}$ is set at the stock's price at the previous time step plus (minus) an increment proportional to the price difference computed in the time window $\tau_{i}$, as shown in equation 4 . The expected increment (or decrement) of the price is divided by the window length and then multiplied by the same $k$ used for random traders in equation 2. In this way, the trend is always computed proportionally to an estimate of the derivative of prices. 


$$
l_{i}=p(t) \cdot\left[1+k \cdot \frac{p(t)-p(t-\tau)}{\tau p(t-\tau)}\right] .
$$

If a transaction tax is levied, the current price $p(t-1)$ is adjusted adding (or subtracting) the tax to (from) it to account for the tax effect.

If a momentum trader decides to sell, the quantity of assets that $\mathrm{s} /$ he can sell, $q_{i}^{s}$, cannot exceed the amount of assets $a_{i}(t)$ owned by the trader $i$. If a momentum trader decides to buy, the maximum purchasable quantity $q_{i}^{b}$ is limited by the cash $c_{i}(t)$. Both $q_{i}^{s}$ and $q_{i}^{b}$ are computed proportionally to the absolute value of an estimate of the derivative of prices, as shown in equations 5 and 6 :

$$
\begin{gathered}
q_{i}^{s}=a_{i}(t) \cdot U(0,1) \cdot\left[1+k \cdot \frac{|p(t)-p(t-\tau)|}{\tau p(t-\tau)}\right] \\
q_{i}^{b}=\frac{c_{i}(t)}{p_{i}(t)} \cdot U(0,1) \cdot\left[1+k \cdot \frac{|p(t)-p(t-\tau)|}{\tau p(t-\tau)}\right] .
\end{gathered}
$$

where $U(0,1)$ is a random draw from a Uniform Distribution between 0 and 1 .

\subsubsection{Contrarian traders}

Contrarian traders (type C) are trend-followers too, but they speculate that, if the stock price is rising, it will stop rising soon and fall, so it is better to sell near the maximum, and vice versa. A time window $\left(\tau_{i}\right)$ is assigned to each contrarian trader at the beginning of the simulation in the same way as for momentum traders. The contrarian trader's order limit price and quantity are computed in the same fashion as the momentum traders, but in the opposite direction. The transaction tax is dealt with in the same way as for momentum traders.

\subsection{Price clearing mechanism}

The price clearing mechanism of each market is based on the intersection of the demand-supply curve. At each simulation step, the traders issue their buy or sell orders with their limit prices, computed as described in section 2.1. We adopted the algorithm described in Raberto et al. (2001), where price clearing is obtained by the intersection of supply and demand curves. 
Let $\left(a_{u}^{b}, b_{u}\right), u=1, \ldots, U$, be the data associated with the $U$ buy orders. In each pair, the quantity of stock to buy, $a_{u}^{b}$, is associated with its limit price, $b_{u}$. As regards the $V$ selling orders, they are represented by pairs: $\left(a_{v}^{s}, s_{v}\right)$, $v=1, \ldots, V$. Here the quantity to sell is $a_{v}^{s}$, while its associated limit price is $s_{v}$. The cleared price, $p^{*}$, is determined by intersecting two functions:

$$
\begin{aligned}
f_{t+1}(p) & =\sum_{u \mid b_{u} \geq p} a_{u}^{b} \quad \text { (Demand curve) } \\
g_{t+1}(p) & =\sum_{v \mid s_{v} \leq p} a_{v}^{s} \quad \text { (Supply curve). }
\end{aligned}
$$

The orders matching the new price $p^{*}$ (i.e., buy orders with maximum price lower than or equal to $p^{*}$, and selling orders with minimum price higher than or equal to $p^{*}$ ) are executed. Subsequently, the amount of cash and assets owned by each trader is updated.

\subsection{Attraction functions}

In the case study of two markets, at each simulation step $(t)$, the trader decides in which market $\mathrm{s} /$ he prefers to trade by evaluating an attraction function for both markets. Let $A_{1}^{T, i}(t)$ and $A_{2}^{T, i}(t)$ be the attraction functions for the ith generic trader of type $T$ for the first and second market, respectively. At each step, the $\mathrm{i}$-th trader chooses the first market with probability $\pi_{1}^{i}(t)=$ $\frac{A_{1}^{T, i}(t)}{A_{1}^{T, i}(t)+A_{2}^{T, i}(t)}$, and the second one with probability $\pi_{2}^{i}(t)=1-\pi_{1}^{i}(t)$.

In most simulations, the trader populations of two markets do not differ significantly, no more than a few percentage points. However, in about $1-2 \%$ cases, it may happen that one market becomes too attractive compared to the other, triggering an avalanche of traders and leaving empty (or almost empty) the other market. To avoid this divergent behavior, we constrained the values of the probability function $\pi_{1}^{i}(t)$ to a minimum set at 0.3 . This value is somewhat arbitrary, but it is sufficient to obviate the problem completely without introducing any significant side-effect in the simulations.

As regards attraction functions, they have been designed taking into account the specific characteristics of various kinds of traders.

Random traders represent the bulk of traders operating in the market for personal reasons or with no specific trading strategy. When faced with the possibility of operating in one of two markets, they naturally tend to prefer the less volatile one. Moreover, they also tend to avoid the market with higher tax 
rate. In our model, at each simulation step random traders choose randomly to buy or sell with equal probability. If a random trader decides to sell, her/his attraction function reflects the considerations made above and is shown in equation 9:

$$
A_{j, \text { sell }}^{R, i}=e^{\sigma_{j}^{2}\left(\tau_{i}\right)}\left(1-\operatorname{tax}_{j}\right)
$$

The superscript $R$ denotes the random trader, $j$ denotes the j-th asset, and $\sigma_{j}^{2}\left(\tau_{i}\right)$ represents the volatility of the returns computed in the time window $\tau_{i}$ specific for each trader. The exponential term ensures that random traders prefer to sell in a volatile market. The $\left(1-\operatorname{tax}_{j}\right)$ term reduces the attraction of a taxed market, with $\operatorname{tax}_{j}$ being the transaction tax imposed in $j-$ th market. For instance, if the tax is $1 \%$ in market $j$, the term $\operatorname{tax}_{j}$ is set at 0.01 .

If a random trader decides to buy, $\mathrm{s} /$ he performs this action in a less volatile market with a higher probability. Thus, the probability that a random trader buys in a less volatile market is equal to the probability that a random trader sells in a more volatile one. The attraction function is given by equation 10 :

$$
A_{j, \text { buy }}^{R, i}=e^{-\sigma_{j}^{2}\left(\tau_{i}\right)}\left(1-\operatorname{tax}_{j}\right) .
$$

Fundamental analysis requires a deep knowledge of the market. Fundamentalists thus tend to concentrate on a limited number of markets (Westerhoff 2004). In our model, each fundamentalist issues orders in one market only where $\mathrm{s} /$ he is more knowledgeable, so for each of them the attraction function of one market is one, and that of the other market is zero. The fundamentalist traders' population, as well as their total initial wealth, is equally divided between the two markets.

Momentum and contrarian traders are trend-followers, so they choose the market depending on the trend of past prices. Basically they prefer the market with the highest trend, computed in their time window $\tau_{i}$. They also take into account the transaction tax rate in the same way as random traders. These choices are reflected in the attraction function reported in equation 11:

$$
A_{j}^{M, i}=A_{j}^{C, i}=e^{\frac{\left|p_{j}(t)-p_{j}\left(t-\tau_{i}\right)\right|}{\tau_{i} p_{j}\left(t-\tau_{i}\right)}}\left(1-t a x_{j}\right) .
$$




\section{Results}

In this section we describe the results of the computational experiments we performed.

We studied the effectiveness of the Tobin tax in two steps. In section 3.1 we discuss one market only, first without the tax, then levying a tax rate between $0.05 \%$ and $0.5 \%$ on each transaction.

In section 3.2 we discuss two markets, first with no tax applied, and then applying the tax to the first.

We performed numerous simulations for all cases. Each simulation is usually run with 4,000 time steps (corresponding to a time span of 16 years), and with 400 agents, each with a probability $p=0.1$ to trade at each time step. We also performed some simulation runs with 4000 agents, each with a probability $p=0.01$ to trade at each time step. In this way, the average number of market transactions is the same as the previous case, but each trader places on average ten times fewer transactions, thus maintaining virtually unchanged his/her wealth irrespective of the trading strategy and of the tax.

Traders' initial endowment (both in cash and stocks) was obtained by dividing agents into groups of 20 traders and applying Zipf's law to each group. We found that an unequal initial endowment increases trading volumes and generates logarithmic returns with fatter tails. On the other hand, in the real world market traders' wealth is unequally distributed. In the case of one market, each trader is given an average $\$ 50000$ cash ( $\$ 70000$ for two markets) and in both cases an average 1000 stocks (per market).

At the beginning of the simulation, the starting price of the asset (and the fundamental price used by fundamentalists) is set at a value equal to the total wealth divided by the number of assets and multiplied by the square root of the number of markets. This value has been found to be the "equilibrium" value for markets with only random traders.

For each trader configuration we performed 20 runs. In some cases, we also performed 50 runs, but we never found results to differ significantly from those obtained with 20 runs.

\subsection{One market}

As described in 3.1.1 and 3.1.2 we first tested the overall behavior of our model, varying the percentage of fundamentalists from zero to $30 \%$ in steps of 10 and 
the percentage of chartists from zero to $30 \%$ in a similar fashion. Note that chartists always comprise the same percentage of momentum and contrarian traders. Then we tested our model keeping the percentage of fundamentalists $(20 \%)$ and of chartists $(20 \%)$ unchanged but varying the percentage of momentum versus contrarian traders in $5 \%$ steps.

\subsubsection{One market with no transaction tax}

When the tax is not levied in a closed market, we obtained results similar to those reported in Raberto et al. (2003) with fundamentalists and contrarian traders gaining wealth with time at the expense of momentum traders and, to a lesser extent, of random traders. Price series show the usual "styilized facts", with fat tails of returns and volatility clustering. For the sake of brevity, these results are not reported here. Note that, as discussed in section 2.1, the trader models are not the same as previous reported simulations (Raberto et al. 2003), but now all depend on the same coefficient $k$, which is able to control traders' reaction to price trend and thus to tune market volatility. After many test runs, we set the value of $k$ at 1.9, which guarantees the appearance of the price series stylized facts for virtually every trader composition used. As regards price variance, with the new method it exhibits values higher than those of real markets, yielding price variations two or three times higher. However, we believe that this feature could be useful to ascertain more clearly the effect of the tax on volatile markets.

In Fig. 1(a) we plot the histogram of daily log-returns. A best-fit normal distribution is superimposed; its narrow peak is well defined and is typical of all simulations we ran. Fig. 1(b) shows the survival probability distribution of the standardized logarithmic return. The solid line represents the survival probability distribution of the best Gaussian fit and the bold stars that of the returns. The deviation from Gaussian distribution shows again a leptokurtotic behavior in the returns tail, with a very well-defined power-law behavior for high values of returns.

Here we describe the results of several simulations, varying the percentage of fundamental and chartist traders from $0 \%$ to $30 \%$ in steps of $10 \%$, the remainder being random traders.

Table 1 shows the mean and standard error of price volatility, computed for the case of no Tobin tax.

Volatility of the returns was computed as the variance during period $T$ :

$$
\sigma_{r}^{2}=\frac{1}{T-1} \sum_{t=1}^{T}\left(r_{t}-\bar{r}\right)^{2}
$$




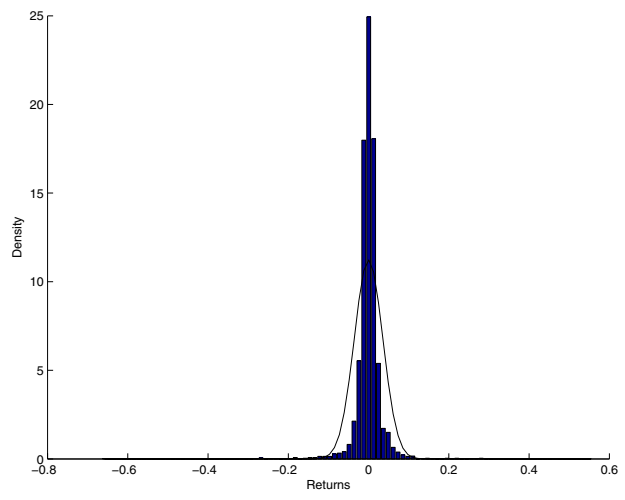

(a) Histogram

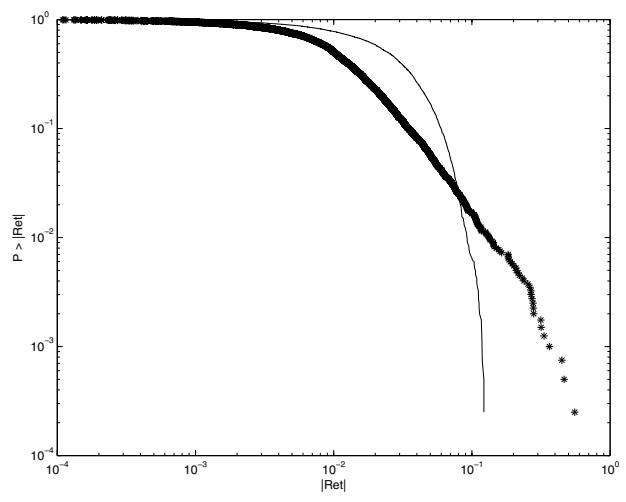

(b) Survival

Fig. 1. Histogram of the distribution of daily log-returns superimposed on the best normal fit (left) and survival probability distribution (right).

where $r_{t}=\ln (p(t))-\ln (p(t-1))$ represents the logarithmic returns at the instant $t$. We always omitted the first 250 simulation steps in price volatility computation to accommodate possible initial transient effects on price volatility.

As regards the width of time window $T$, we performed various tests, varying $T$ between 5 and 50 time steps. In all cases, irrespectively of trader composition and tax value, we found very stable average price variance values, slowly decreasing with $T$. The percentage difference of average price volatility between $T=5$ and $T=50$ is always below $12 \%$. We then decided to use the value $T=10$, which guarantees the best trade-off between low and high values of the time window used to compute price volatility.

Table 1

Mean and standard error of volatility in a single market with no tax. The results are multiplied by $10^{3}$.

\begin{tabular}{c||c|c|c|c}
\multicolumn{1}{c||}{} & \multicolumn{5}{c}{ Chartist } \\
\cline { 2 - 5 } Fundamentalist & $\mathbf{0 \%}$ & $\mathbf{1 0 \%}$ & $\mathbf{2 0 \%}$ & $\mathbf{3 0 \%}$ \\
\hline \hline $\mathbf{0 \%}$ & $1.61(0.21)$ & $0.78(0.10)$ & $0.46(0.07)$ & $0.19(0.01)$ \\
\hline $\mathbf{1 0 \%}$ & $4.33(0.44)$ & $1.42(0.16)$ & $0.49(0.03)$ & $0.22(0.01)$ \\
\hline $\mathbf{2 0 \%}$ & $7.31(0.62)$ & $2.41(0.31)$ & $0.60(0.06)$ & $0.27(0.04)$ \\
\hline $\mathbf{3 0 \%}$ & $15.17(0.99)$ & $2.94(0.33)$ & $1.00(0.10)$ & $0.26(0.02)$
\end{tabular}

The results of the simulations are reported in Table 1 . In these runs, price volatility decreases as the percentage of chartists increases, and increases as the percentage of fundamentalists decreases. These results are fairly robust and repeatable because the presented figures are each averaged over 20 runs, and their standard error is usually much lower than volatility itself. Since they are not obvious, we will discuss them in detail. 
In our model, random traders alone are able to create consistent price volatility, for two main reasons:

- their wealth is distributed according to Zipf's law, so from time to time the wealthiest traders place large orders that are able to generate significant price variations;

- the limit price of orders is randomly chosen according to a Gaussian distribution with variance depending on past price volatility; this introduces a GARCH-like effect, able to yield volatility clustering and to increase overall price volatility.

On the other hand, chartists are composed equally of momentum and contrarian traders. While momentum traders can destabilize the market and thus increase its volatility, contrarian traders tend to stabilize it, basically counteracting the effect of momentum traders. The joint behavior of both populations tends to stabilize the market with respect to the effect of random traders, whose number decreases as the total number of chartists increases.

As regards fundamentalists, price volatility increases sharply as their percentage increases. This phenomenon is related with the prompt intervention of fundamentalists when prices diverge from their fundamental value. In practice, occasional major price variations caused by large orders placed by random traders with a limit price that differs substantially from the current price are immediately counter-acted by fundamentalists, their strength being proportional to the original variation. This behavior drives prices toward the fundamental value, thus adding volatility to the system. Indeed, fundamentalists can be seen as "short memory" traders since they only look at the last price realized. The destabilizing behavior of "short memory" traders is in line with the findings of other agent-based investigations.

In Fig. 2 we report the dynamics of wealth of the four populations of traders for a simulation of 2000 steps. Here both fundamentalists and chartists account for $10 \%$ of total trader population. Fundamentalists and contrarian traders tend to increase their wealth at the expense of momentum traders and, to a lesser extent, of random traders, confirming again the results reported in Raberto et al. (2003) The decreasing wealth of momentum traders, however, does not substantially affect their behavior and their effect on the price.

\subsubsection{One market with transaction tax}

Here we show the effects of the tax on a single market. We performed numerous runs, varying the percentages of trader populations and tax rate. The tax rate is set at $0.1 \%$ and $0.5 \%$. The former figure is within the range usually proposed and discussed by supporters and detractors of a transaction tax, while the latter figure is much higher and is used to analyse the effects of an amplified 


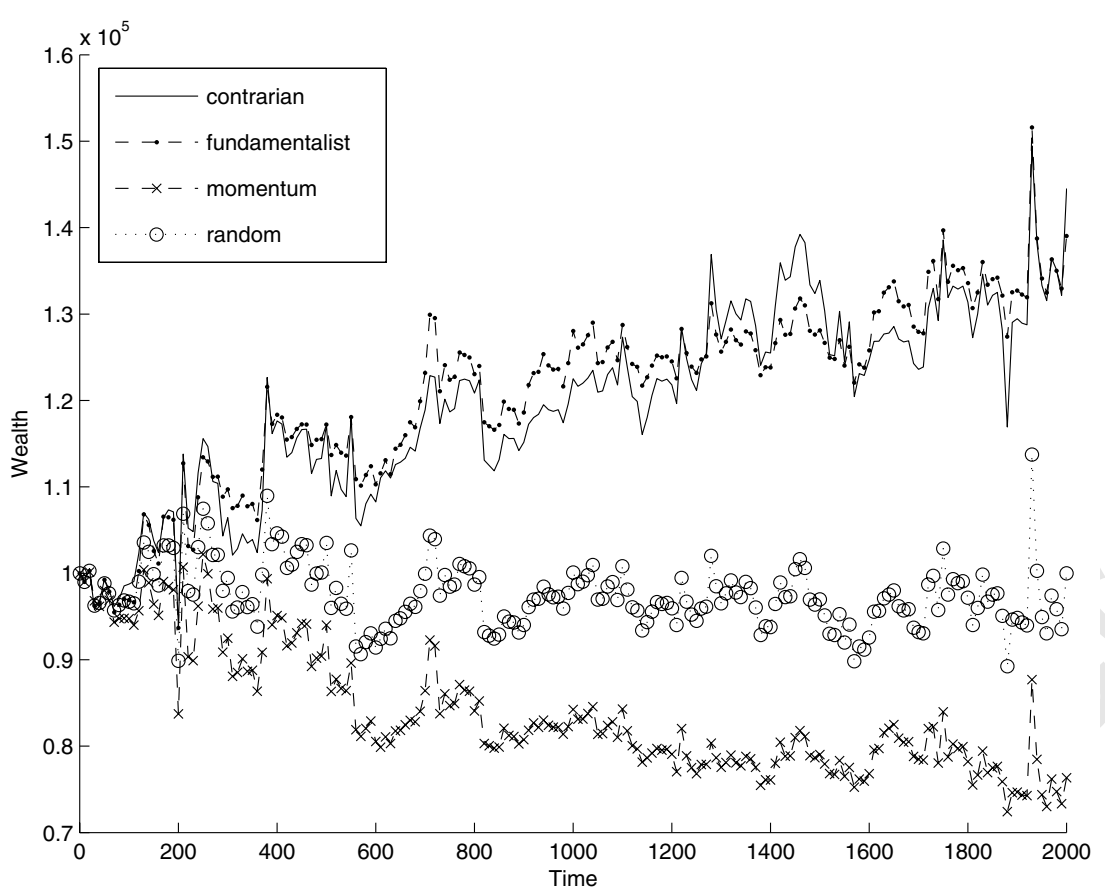

Fig. 2. Dynamics of wealth of the four populations of traders for a simulation of 2000 steps.

tax. Note that since both buyer and seller pay the tax, all these figures should be doubled.

Introducing the tax in one market made it possible to analyze a number of issues debated among its supporters and detractors, namely whether the taxed market becomes more stable and how volatility and trading volumes change. In all reported cases, the simulations show the stylized facts of price series (return autocorrelation, fat tails, volatility clustering).

The results show the price volatility and its standard error averaged over 20 runs each. The simulations were performed using 400 traders and 2000 time steps, varying the percentages of the trader populations as in the previous section.

Since our market model has finite resources, levying a tax leads to a reduction of total traders' wealth with time, perhaps significantly for the highest tax rates. To compensate for this effect, we computed the cash outflow due to the tax every 100 steps and gave randomly chosen traders small amounts of cash totalling their cash outflow.

Table 2 shows mean and standard errors of price volatility computed for a Tobin tax of $0.1 \%$. In this case, for low (10\%) or zero chartist percentage, there are no significant differences compared to the no tax market. As the chartist percentage increases, however, volatility increases substantially except when no fundamentalists are included. This increase may be as much as $80 \%$, for 
the largest percentage of fundamentalist and chartist traders.

Table 2

Mean and standard error of volatility in a single market with $0.1 \%$ tax. The results are multiplied by $10^{3}$.

\begin{tabular}{c||c|c|c|c}
\multicolumn{1}{c||}{} & \multicolumn{4}{c}{ Chartist } \\
\cline { 2 - 5 } Fundamentalist & $\mathbf{0 \%}$ & $\mathbf{1 0 \%}$ & $\mathbf{2 0 \%}$ & $\mathbf{3 0 \%}$ \\
\hline \hline $\mathbf{0}$ & $1.62(0.14)$ & $0.70(0.04)$ & $0.45(0.04)$ & $0.28(0.03)$ \\
\hline $\mathbf{1 0 \%}$ & $3.71(0.33)$ & $1.35(0.14)$ & $0.60(0.07)$ & $0.31(0.01)$ \\
\hline $\mathbf{2 0 \%}$ & $7.78(0.79)$ & $2.44(0.25)$ & $0.74(0.08)$ & $0.36(0.03)$ \\
\hline $\mathbf{3 0 \%}$ & $14.44(1.35)$ & $2.99(0.28)$ & $1.32(0.16)$ & $0.56(0.04)$
\end{tabular}

Table 3 shows mean and standard error of price volatility, computed for a Tobin tax of $0.5 \%$.

Table 3

Mean and standard error of volatility in a single market with $0.5 \%$ tax. The results are multiplied by $10^{3}$.

\begin{tabular}{c||c|c|c|c}
\multicolumn{1}{c||}{} & \multicolumn{5}{c}{ Chartist } \\
\cline { 2 - 5 } Fundamentalist & $\mathbf{0 \%}$ & $\mathbf{1 0 \%}$ & $\mathbf{2 0 \%}$ & $\mathbf{3 0 \%}$ \\
\hline \hline $\mathbf{0}$ & $1.06(0.16)$ & $0.85(0.09)$ & $0.66(0.03)$ & $0.71(0.04)$ \\
\hline $\mathbf{1 0 \%}$ & $3.06(0.41)$ & $1.36(0.12)$ & $1.15(0.10)$ & $1.04(0.09)$ \\
\hline $\mathbf{2 0 \%}$ & $5.74(0.56)$ & $2.73(0.25)$ & $1.89(0.15)$ & $1.55(0.11)$ \\
\hline $\mathbf{3 0 \%}$ & $11.05(0.64)$ & $5.51(0.28)$ & $3.12(0.24)$ & $2.25(0.12)$
\end{tabular}

For markets with random and fundamentalist traders alone, levying the tax produces a small reduction in volatility, that varies with fundamentalist percentage, attaining $5-8 \%(\operatorname{tax}=0.1 \%)$ and as much as $30-40 \%(\operatorname{tax}=0.5 \%)$.

When chartists are taken into account, the tax systematically leads to an increase in volatility of up to $80 \%$ in the case of tax $=0.1 \%$ and of up to 7 -fold for $\operatorname{tax}=0.5 \%$ for the highest percentage of chartists. This effect is evident for a chartist percentage of $20 \%$ or $30 \%$. When chartists account for only $10 \%$ of the entire trader population, the increase in volatility is significant only for a $30 \%$ fundamentalist market. In general, when chartist are included, increasing the percentage of fundamentalists further increases the volatility when the tax is levied.

To gain more insight to this behavior, we performed several runs with a market model composed of $10 \%$ fundamentalists, $5 \%$ momentum traders and $5 \%$ contrarian traders, varying the tax from 0 to $1 \%$ in steps of $0.025 \%$. Each 
tax percentage has been simulated 10 times, and the resulting price variances averaged. The results shown in Figure 3 clearly indicate the steady increase in volatility, despite the noise in measurements, confirming the results reported above.

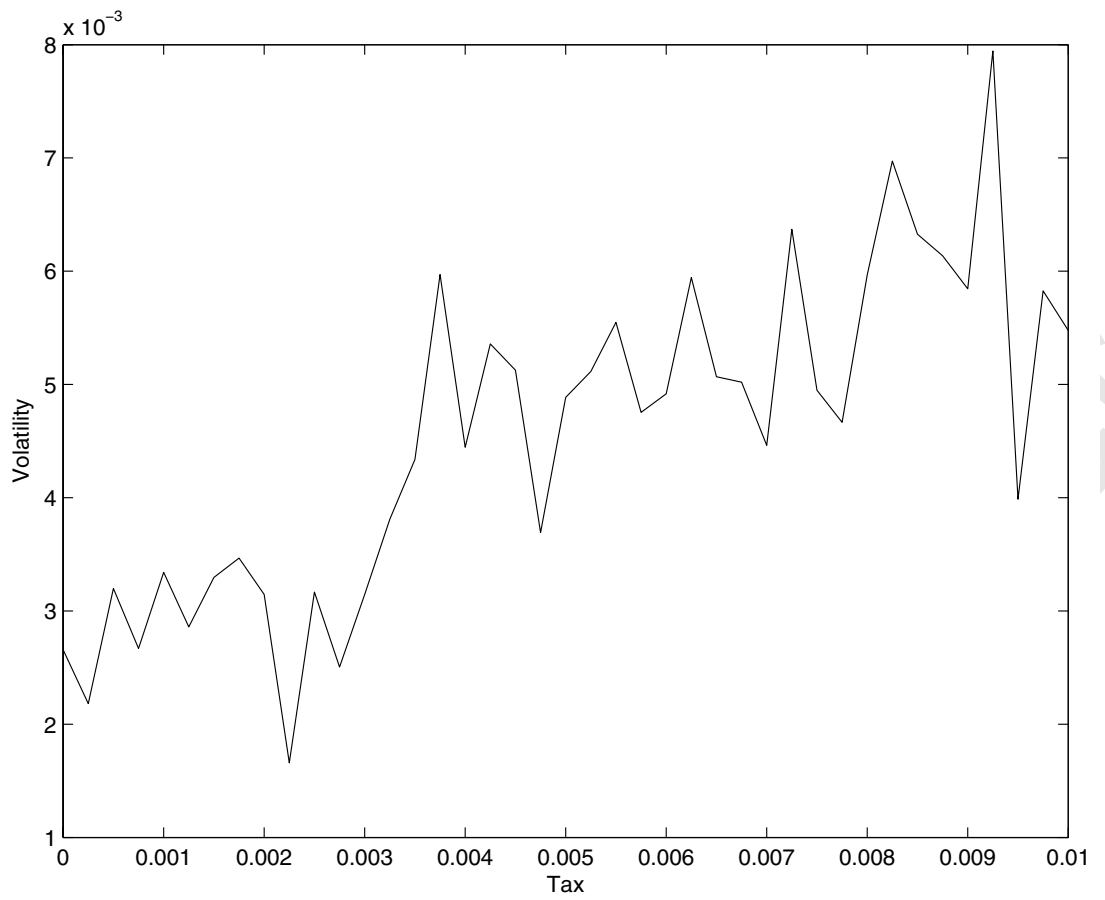

Fig. 3. Price variance as a function of tax rate for $10 \%$ fundamentalist and $10 \%$ chartist traders.

Using this model, price volatility increases steadily with the tax rate, provided that the percentage of chartists is sufficiently large. When chartists are excluded, price volatility tends to decrease slowly with increasing tax rate. These results are in agreement with the empirical findings reported by Umlauf (1993) and by Aliber et al. (2003), who observed a price volatility increase with tax rate (or, better, with transaction costs).

We conducted further tests keeping the percentage of fundamentalists (20\%) and of chartists $(20 \%)$ unchanged, but varying that of momentum versus contrarian traders in $5 \%$ steps.

The results of these simulations are shown in Table 4. We found volatility increased with tax rate in all cases except when contrarian traders were omitted. With this model, an "extreme" chartist composition, made up of contrarian or momentum traders alone, seems to increase volatility, while more balanced compositions result in lower volatility. Momentum traders tend to increase volatility more, especially when no tax, or a small tax, is levied.

Fig. 4 shows the daily time series of logarithmic price returns for a typical simulation having a trader population composed of $20 \%$ fundamentalist, $10 \%$ 
Table 4

Mean and standard error of volatility computed for different contrarian traders percentages, $p_{c}$. The total percentage of chartists is always 20\%. All values are multiplied by $10^{3}$.

\begin{tabular}{c||c|c|c|c|c}
$\begin{array}{c}\text { Tax } \\
\text { rate \% }\end{array}$ & $\begin{array}{c}p_{c}=20 \% \\
\text { Mean (stEr) }\end{array}$ & $\begin{array}{c}p_{c}=15 \% \\
\text { Mean (stEr) }\end{array}$ & $\begin{array}{c}p_{c}=10 \% \\
\text { Mean (stEr) }\end{array}$ & $\begin{array}{c}p_{c}=5 \% \\
\text { Mean (stEr) }\end{array}$ & $\begin{array}{c}p_{c}=0 \% \\
\text { Mean (stEr) }\end{array}$ \\
\hline \hline $\mathbf{0 . 0}$ & $1.83(0.13)$ & $0.62(0.07)$ & $0.58(0.06)$ & $1.15(0.11)$ & $4.88(0.46)$ \\
$\mathbf{0 . 1}$ & $1.96(0.28)$ & $0.95(0.08)$ & $0.71(0.07)$ & $1.25(0.09)$ & $4.31(0.26)$ \\
$\mathbf{0 . 5}$ & $4.70(0.31)$ & $2.26(0.14)$ & $1.84(0.14)$ & $2.20(0.19)$ & $4.78(0.26)$
\end{tabular}
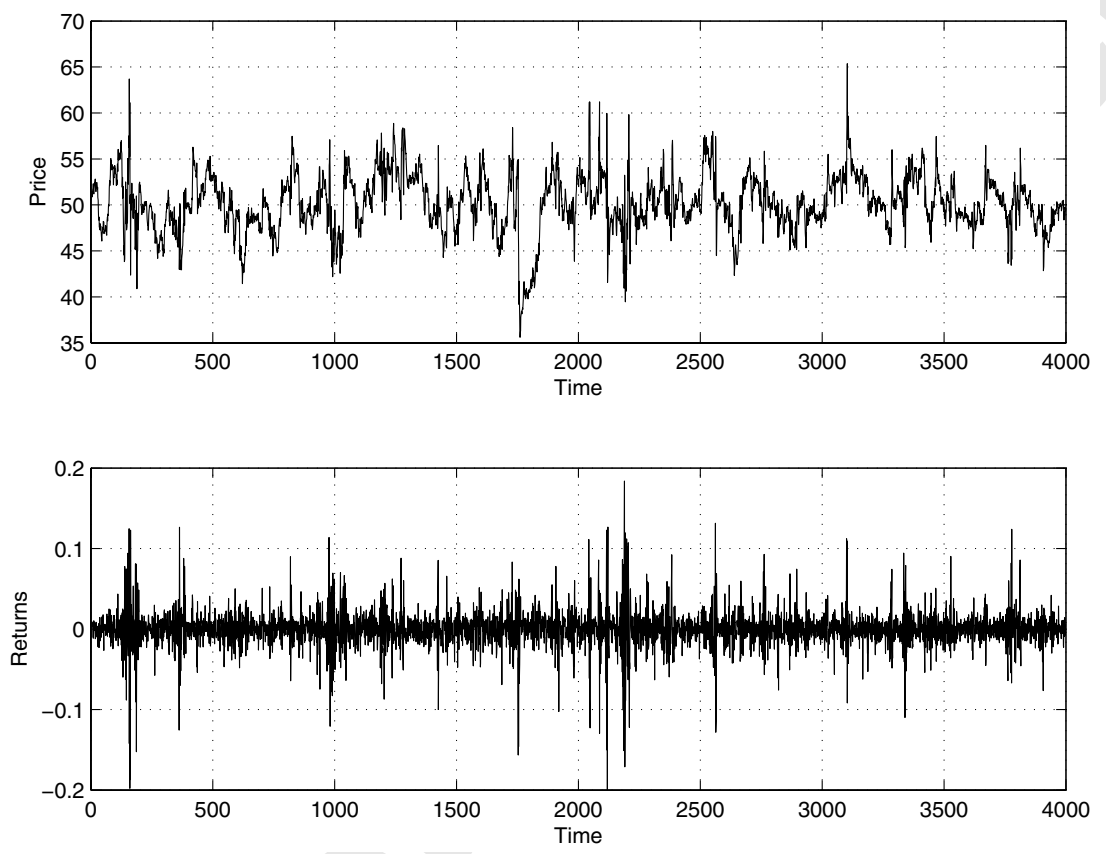

Fig. 4. Daily time series for prices (top) and returns (bottom).

momentum, and $10 \%$ contrarian for a $0.05 \%$ tax rate. Note that prices always oscillate around 50 because the finite amount of cash and stocks induces meanreversion on prices around a constant long-run mean that depends on the ratio of the total amount of cash to the total number of shares (Raberto et al. 2003). Moreover, the fundamental price $p(f)$ of fundamentalist traders is set to 50 to be consistent with the mean reverting behavior.

In our model, the increase of volatility could be explained by the reduction of orders when a tax is applied. Note that we have 400 agents and on average 40 active agents at each time step, resulting in an average of 20 sell orders and 20 buy orders of different sizes. If transaction taxes reduce these numbers as well as the agents' trading amount, the demand and supply curves from which the price is derived becomes much fuzzier, magnifying price variations. The relationship between transaction taxes, market depth and price volatility 
is also explored by Ehrenstein et al. (2005), yielding similar results.

In Tables 5, 6 and 7, we report the average daily volumes for the cases studied. The traded volumes do not change as much as volatility when trader composition and tax rate are varied. However, note the strong anti-correlation between volatility and volumes in many cases.

Table 5

Mean and standard error of daily volumes in a single market with $0.0 \%$ tax. The results are multiplied by $10^{3}$.

\begin{tabular}{c||c|c|c|c}
\multicolumn{1}{c||}{} & \multicolumn{4}{c}{ Chartist } \\
\cline { 2 - 5 } Fundamentalist & $\mathbf{0 \%}$ & $\mathbf{1 0 \%}$ & $\mathbf{2 0 \%}$ & $\mathbf{3 0 \%}$ \\
\hline \hline $\mathbf{0 \%}$ & $9.51(0.91)$ & $10.04(0.96)$ & $10.63(1.00)$ & $11.17(1.06)$ \\
\hline $\mathbf{1 0 \%}$ & $8.02(0.75)$ & $8.69(0.83)$ & $9.28(0.90)$ & $9.94(0.97)$ \\
\hline $\mathbf{2 0 \%}$ & $6.92(0.65)$ & $7.54(0.74)$ & $8.19(0.82)$ & $8.76(0.89)$ \\
\hline $\mathbf{3 0 \%}$ & $5.80(0.56)$ & $6.43(0.66)$ & $7.12(0.75)$ & $7.69(0.83)$
\end{tabular}

Table 6

Mean and standard error of daily volumes in a single market with $0.1 \%$ tax. The results are multiplied by $10^{3}$.

\begin{tabular}{c||c|c|c|c}
\multicolumn{1}{c||}{} & \multicolumn{4}{c}{ Chartist } \\
\cline { 2 - 5 } Fundamentalist & $\mathbf{0 \%}$ & $\mathbf{1 0 \%}$ & $\mathbf{2 0 \%}$ & $\mathbf{3 0 \%}$ \\
\hline \hline $\mathbf{0 \%}$ & $9.51(0.91)$ & $9.82(0.93)$ & $10.07(0.96)$ & $10.18(0.99)$ \\
\hline $\mathbf{1 0 \%}$ & $8.06(0.75)$ & $8.41(0.80)$ & $8.75(0.85)$ & $8.91(0.90)$ \\
\hline $\mathbf{2 0 \%}$ & $6.85(0.64)$ & $7.27(0.71)$ & $7.57(0.77)$ & $7.70(0.82)$ \\
\hline $\mathbf{3 0 \%}$ & $5.76(0.55)$ & $6.16(0.64)$ & $6.44(0.69)$ & $6.57(0.74)$
\end{tabular}

Table 7

Mean and standard error of daily volumes in a single market with $0.5 \%$ tax. The results are multiplied by $10^{3}$.

\begin{tabular}{c||c|c|c|c}
\multicolumn{1}{c||}{} & \multicolumn{4}{c}{ Chartist } \\
\cline { 2 - 5 } Fundamentalist & $\mathbf{0 \%}$ & $\mathbf{1 0 \%}$ & $\mathbf{2 0 \%}$ & $\mathbf{3 0 \%}$ \\
\hline \hline $\mathbf{0 \%}$ & $9.87(0.88)$ & $9.30(0.85)$ & $8.82(0.85)$ & $8.41(0.88)$ \\
\hline $\mathbf{1 0 \%}$ & $8.16(0.73)$ & $7.78(0.72)$ & $7.35(0.73)$ & $7.01(0.76)$ \\
\hline $\mathbf{2 0 \%}$ & $6.88(0.63)$ & $6.57(0.64)$ & $6.19(0.65)$ & $5.88(0.67)$ \\
\hline $\mathbf{3 0 \%}$ & $5.73(0.55)$ & $5.44(0.56)$ & $5.15(0.58)$ & $4.87(0.61)$
\end{tabular}

Westerhoff (2003), using a different model with unlimited resources, observed a different behavior: a reduction in volatility for low tax rates that increased 
as rates increased. These results confirm how difficult it is to assess the impact of a change in market regulation using a theoretical model, suggesting further studies are warranted to gain a greater insight into market behavior.

\subsection{Two markets}

In this subsection we discuss the second part of our experiment. We analyzed two markets, first levying no transaction tax and then introducing the tax in one market, leaving the other untaxed. The rules enabling traders to switch from one market to the other are described in Section 2.3. We recall that fundamentalist traders do not switch between markets.

Traders' initial cash and stock endowment was chosen with the constraint that wealth was balanced in the two markets. We performed a number of simulations varying fundamentalist and chartist percentages between 0 and 20 , maintaining the same percentage of momentum and contrarian traders. In this way, we had a "thermal bath" of random traders, and at the same time a sufficiently large number of other kinds of traders to make their influence felt in the price dynamics.

The number of traders used in each simulation was 4000 , with a $2 \%$ probability of trading at each time step. In this way, we were able to generate for each market the same average number of orders as in the simulations for a single market. Note that we had 400 traders in the single market simulations, with a $10 \%$ probability of trading at each time step. The much larger number of traders was chosen to minimize any possible side-effects caused by a wealth increase or reduction for specific trader kinds.

Each configuration was simulated 20 times, using 2000 time steps each, and we computed the average price variance (volatility) and the standard error of this variance to assess price volatility data consistency. The variance has been computed for intervals of 10 time steps, discarding the first 250 steps, as in previous runs.

\subsubsection{Two markets: no transaction tax}

Here we examine the dynamics of two markets with no transaction tax. When no tax is levied in neither of the closed markets, we obtain the classical stylized facts (returns autocorrelation, fat tails, volatility clustering) observed for the single market. For the sake of brevity, these results are not reported here.

Tables 8 and 9 give the mean and the standard error of price volatility, computed for the case of no Tobin tax and varying the percentages of fundamen- 
talists and chartists.

The price volatility values confirm that both markets behave in the same way. Moreover, in this case the number of traders switching from one market to another, and vice-versa, are balanced in both markets. Volatility is somewhat higher than in the corresponding Table 1, denoting that the presence of two markets, with traders switching between them, tends to increase price volatility. Again, price volatility decreases with increasing percentages of chartists and increases with increasing percentages of fundamentalists. These experiments confirm the findings obtained for single markets and two markets with no tax. The first observation is that having two markets leads to a substantial increase in price volatility. This phenomenon might be explained by the imbalance between cash and stocks with respect to a single market. However, we performed a number of simulations with one market, varying traders' initial cash endowment while leaving their stock endowment unchanged, but did not notice any change in volatility. Note that volatility increases 3-4 fold even for markets with only random traders, who switch from one to the other trying to reduce their risk. They tend to sell in the more volatile market and buy in the less volatile one, as shown in equations 9 and 10 (section 2.3). Probably, this behavior creates an imbalance in orders resulting in an overall increase in volatility. The intrinsic mean reversion mechanism due to limited traders resources avoids long-term imbalance between the two markets. The presence of fundamentalists seems to reduce the increase in volatility, while the combined presence of high percentages of chartists and fundamentalists magnifies it; for $20 \%$ fundamentalists and $20 \%$ chartists, we observed a 8-9 fold increase (see Tables 1, 8 and 9).

Table 8

Mean and standard error of volatility in market one. The results are multiplied by $10^{3}$.

\begin{tabular}{c||c|c|c|c}
\multicolumn{1}{c||}{} & \multicolumn{5}{c}{ Chartist } \\
\cline { 2 - 5 } Fundamentalist & $\mathbf{0 \%}$ & $\mathbf{5 \%}$ & $\mathbf{1 0 \%}$ & $\mathbf{2 0 \%}$ \\
\hline \hline $\mathbf{0 \%}$ & $5.62(0.58)$ & $3.72(0.50)$ & $2.04(0.25)$ & $0.67(0.08)$ \\
\hline $\mathbf{5 \%}$ & $8.15(1.34)$ & $4.20(0.61)$ & $1.89(0.28)$ & $0.79(0.15)$ \\
\hline $\mathbf{1 0 \%}$ & $12.18(1.87)$ & $4.88(0.79)$ & $3.92(0.71)$ & $1.07(0.19)$ \\
\hline $\mathbf{2 0 \%}$ & $37.22(3.42)$ & $19.38(2.15)$ & $7.49(0.88)$ & $2.25(0.36)$
\end{tabular}

In Fig. 5 we show the wealth dynamics for the four trader populations in both markets for a simulation of 2000 steps. Both fundamentalists and chartists account for $10 \%$ of total trader population. For the two markets, fundamentalists and contrarian traders tend to increase their wealth at the expense of momentum traders and random traders. The differences in wealth are less pronounced for the single market, but we should recall that in this case the 
Table 9

Mean and standard error of volatility in market two. The results are multiplied by $10^{3}$.

\begin{tabular}{c||c|c|c|c}
\multicolumn{1}{c||}{} & \multicolumn{4}{c}{ Chartist } \\
\cline { 2 - 5 } Fundamentalist & $\mathbf{0 \%}$ & $\mathbf{5 \%}$ & $\mathbf{1 0 \%}$ & $\mathbf{2 0 \%}$ \\
\hline \hline $\mathbf{0 \%}$ & $4.90(0.73)$ & $3.87(0.84)$ & $1.95(0.27)$ & $0.67(0.09)$ \\
\hline $\mathbf{5 \%}$ & $8.12(1.53)$ & $4.07(0.66)$ & $1.88(0.29)$ & $0.74(0.09)$ \\
\hline $\mathbf{1 0 \%}$ & $7.99(1.14)$ & $5.08(0.76)$ & $2.26(0.27)$ & $1.01(0.18)$ \\
\hline $\mathbf{2 0 \%}$ & $35.65(3.22)$ & $17.23(1.87)$ & $7.78(1.02)$ & $2.04(0.48)$
\end{tabular}

number of traders rises to 4000 and tend to trade five times less than for the single market.

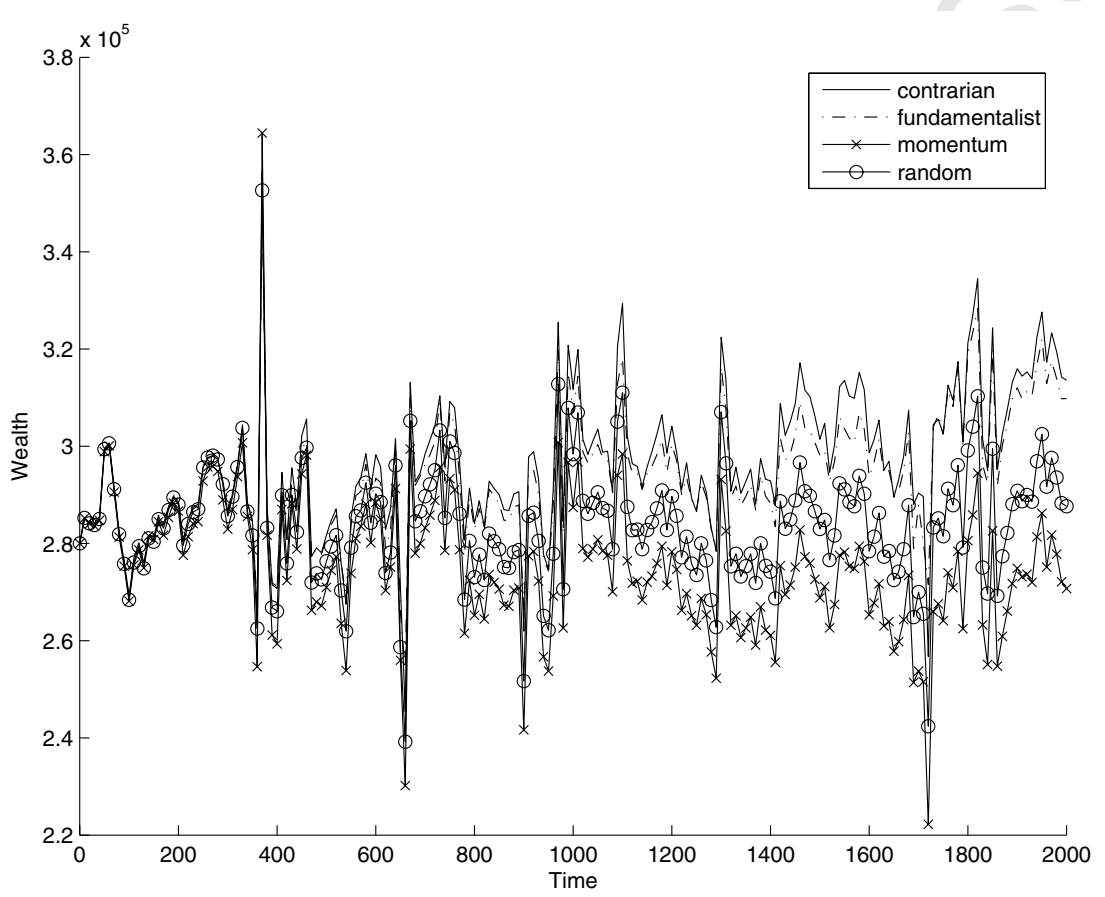

Fig. 5. Wealth dynamics of the four trader populations for a simulation of 2000 steps, for two markets.

\subsubsection{Two markets: transaction tax in one}

Here we discuss the dynamics of two markets, levying the tax in just one of them (Market 1). When levying a tax on Market 1 transactions, we obviously found total traders' wealth to decrease over time because our market model has limited resources. This decrease affects both cash (because the tax is paid in cash) and prices (because a cash shortage affects prices). If the fundamental price $\left(p_{f}\right)$ is not adjusted according to the cash reduction, in a closed market after a while fundamentalists' wealth will also diminish because they tend 
to push prices towards their fundamental value, which eventually becomes unsustainable. They buy all the stocks they can and then stay still while the value of their stocks slowly diminishes. However, in our simulations the cash drain of tax payment is negligible; because the tax rate is low, the number of transactions made by each trader is also low, and the number of simulated time steps is limited. Thus, the reported results are not affected by any cash drain.

Tables 10 and 11 give the mean and standard error of price volatility in markets 1 and 2 respectively, computed for a tax rate of $0.1 \%$ and varying the percentage of fundamentalists and chartists. Tables 12 and 13 show the same configurations and data, this time computed for a tax rate of $0.5 \%$.

Table 10

Mean and standard error of volatility in market one with $0.1 \%$ transaction tax. The results are multiplied by $10^{3}$.

\begin{tabular}{c||c|c|c|c}
\multicolumn{1}{c||}{} & \multicolumn{4}{c}{ Chartist } \\
\cline { 2 - 5 } Fundamentalist & $\mathbf{0 \%}$ & $\mathbf{5 \%}$ & $\mathbf{1 0 \%}$ & $\mathbf{2 0 \%}$ \\
\hline \hline $\mathbf{0 \%}$ & $7.27(0.99)$ & $3.88(0.59)$ & $2.96(0.48)$ & $1.16(0.17)$ \\
\hline $\mathbf{5 \%}$ & $5.88(0.76)$ & $4.38(0.53)$ & $2.23(0.44)$ & $1.36(0.26)$ \\
\hline $\mathbf{1 0 \%}$ & $11.55(1.26)$ & $7.16(1.02)$ & $3.39(0.52)$ & $1.28(0.17)$ \\
\hline $\mathbf{2 0 \%}$ & $43.12(4.44)$ & $16.71(1.87)$ & $10.86(1.30)$ & $2.71(0.52)$
\end{tabular}

Table 11

Mean and standard error of volatility in market two with $0.1 \%$ transaction tax. The results are multiplied by $10^{3}$.

\begin{tabular}{c||c|c|c|c}
\multicolumn{1}{c||}{} & \multicolumn{4}{c}{ Chartist } \\
\cline { 2 - 5 } Fundamentalist & $\mathbf{0 \%}$ & $\mathbf{5 \%}$ & $\mathbf{1 0 \%}$ & $\mathbf{2 0 \%}$ \\
\hline \hline $\mathbf{0 \%}$ & $6.16(0.81)$ & $3.19(0.47)$ & $2.45(0.43)$ & $0.85(0.08)$ \\
\hline $\mathbf{5 \%}$ & $5.77(0.69)$ & $3.89(0.67)$ & $2.80(0.38)$ & $0.68(0.09)$ \\
\hline $\mathbf{1 0 \%}$ & $11.48(1.83)$ & $7.44(1.05)$ & $2.10(0.31)$ & $1.33(0.24)$ \\
\hline $\mathbf{2 0 \%}$ & $36.92(4.61)$ & $17.62(2.29)$ & $7.05(1.05)$ & $1.56(0.19)$
\end{tabular}

The effects of the tax observed for a single market (no substantial differences for random and fundamentalist traders alone, volatility increase in the presence of chartists) are fully confirmed in the case of a tax levied on one market and linked to a second, untaxed market. The increase in volatility is, however, less pronounced, maybe because the market volatility is already very high.

The most significant effect we found is that the taxed market presents a greater volatility than the linked untaxed market in all those cases where levying 
Table 12

Mean and standard error of volatility in market one with $0.5 \%$ transaction tax. The results are multiplied by $10^{3}$.

\begin{tabular}{c||c|c|c|c}
\multicolumn{1}{c||}{} & \multicolumn{4}{c}{ Chartist } \\
\cline { 2 - 5 } Fundamentalist & $\mathbf{0 \%}$ & $\mathbf{5 \%}$ & $\mathbf{1 0 \%}$ & $\mathbf{2 0 \%}$ \\
\hline \hline $\mathbf{0 \%}$ & $6.76(0.92)$ & $5.06(0.65)$ & $3.14(0.44)$ & $2.05(0.26)$ \\
\hline $\mathbf{5 \%}$ & $5.28(0.67)$ & $4.82(0.93)$ & $3.95(0.73)$ & $2.24(0.28)$ \\
\hline $\mathbf{1 0 \%}$ & $11.09(1.57)$ & $6.61(0.83)$ & $5.77(0.88)$ & $3.81(0.66)$ \\
\hline $\mathbf{2 0 \%}$ & $36.10(3.64)$ & $29.09(2.48)$ & $16.26(1.69)$ & $7.28(0.72)$
\end{tabular}

Table 13

Mean and standard error of volatility in market two with $0.5 \%$ transaction tax. The results are multiplied by $10^{3}$.

\begin{tabular}{c||c|c|c|c}
\multicolumn{1}{c||}{} & \multicolumn{4}{c}{ Chartist } \\
\cline { 2 - 5 } Fundamentalist & $\mathbf{0 \%}$ & $\mathbf{5 \%}$ & $\mathbf{1 0 \%}$ & $\mathbf{2 0 \%}$ \\
\hline \hline $\mathbf{0 \%}$ & $5.58(0.61)$ & $4.54(0.79)$ & $1.98(0.29)$ & $0.89(0.15)$ \\
\hline $\mathbf{5 \%}$ & $6.98(1.11)$ & $3.52(0.7)$ & $1.91(0.35)$ & $0.72(0.10)$ \\
\hline $\mathbf{1 0 \%}$ & $12.09(1.84)$ & $3.74(0.60)$ & $4.05(0.74)$ & $1.02(0.24)$ \\
\hline $\mathbf{2 0 \%}$ & $43.63(3.79)$ & $18.06(2.10)$ & $5.92(0.86)$ & $1.10(0.12)$
\end{tabular}

the tax has a major effect, such as in the presence of chartists. For a highly speculative market (i.e., for the higher percentages of chartists), the untaxed market shows a reduction in volatility with respect to the case of no tax market, while the taxed market shows a strong increase, thus "adsorbing" to some extent additional volatility from the former.

Table 14 shows average daily trading volumes in both markets, for different trader compositions and tax rates. The taxed market is, as always, Market 1. The values are averaged over 20 simulations, and standard errors are also given.

As expected, when no tax is levied, average trading volumes do not differ significantly from one market to the other. The introduction of the tax leads to smaller volumes in the taxed market in all those cases where it results in a price volatility increase. The difference in trading volumes is not as large as the difference in volatility, at the most in the order of $20 \%$. This finding confirms, however, that traders tend to shun the taxed market, and that a lower volume triggers an increase in volatility, as discussed in Section 3.1.2. 
Table 14

Average daily volumes. If there is a tax, it is levied on market one only. The results are divided by $10^{3}$

\begin{tabular}{c|c||c|c||c|c||c|c}
\multicolumn{1}{c||}{ Population } & \multicolumn{2}{c||}{ No Tax } & \multicolumn{2}{c||}{$0.1 \%$ Tax } & \multicolumn{2}{c}{$0.5 \%$ Tax } \\
\hline F. & C. & Mkt1 & Mkt2 & Mkt1 & Mkt2 & Mkt1 & Mkt2 \\
\hline \hline $0 \%$ & $0 \%$ & $9.49(1.05)$ & $9.48(1.04)$ & $9.55(1.07)$ & $9.46(1.05)$ & $9.47(1.07)$ & $9.57(1.07)$ \\
\hline $0 \%$ & $10 \%$ & $9.97(1.05)$ & $10.01(1.05)$ & $9.81(1.04)$ & $9.91(1.05)$ & $9.37(1.02)$ & $9.85(1.04)$ \\
\hline $0 \%$ & $20 \%$ & $10.55(1.07)$ & $10.63(1.08)$ & $10.13(1.05)$ & $10.54(1.08)$ & $9.26(1.03)$ & $10.31(1.05)$ \\
\hline $10 \%$ & $0 \%$ & $8.61(0.94)$ & $8.60(0.94)$ & $8.56(0.94)$ & $8.61(0.94)$ & $8.57(0.94)$ & $8.68(0.94)$ \\
\hline $10 \%$ & $10 \%$ & $9.24(0.99)$ & $9.29(0.98)$ & $9.05(0.97)$ & $9.25(0.99)$ & $8.51(0.94)$ & $9.25(0.99)$ \\
\hline $10 \%$ & $20 \%$ & $10.01(1.05)$ & $9.95(1.06)$ & $9.44(1.01)$ & $9.99(1.05)$ & $8.40(0.96)$ & $9.96(1.04)$ \\
\hline $20 \%$ & $0 \%$ & $7.91(0.90)$ & $7.87(0.90)$ & $7.85(0.90)$ & $7.89(0.89)$ & $7.82(0.89)$ & $7.91(0.90)$ \\
\hline $20 \%$ & $10 \%$ & $8.50(0.94)$ & $8.47(0.95)$ & $8.30(0.93)$ & $8.50(0.94)$ & $7.78(0.88)$ & $8.58(0.95)$ \\
\hline $20 \%$ & $20 \%$ & $9.17(1.00)$ & $9.12(0.99)$ & $8.76(0.98)$ & $9.21(1.01)$ & $7.77(0.92)$ & $9.27(1.01)$
\end{tabular}

\section{Conclusions}

In this paper we have presented a study on the impact of securities transaction taxes in financial markets, performed using an artificial stock market. We used a simple market model with four kinds of agents, that model typical traders' behavior in financial markets: random traders, fundamentalists, and two kinds of chartists. The market model is closed, as each trader is given a limited amount of cash and stocks. The price clearing mechanism matches supply and demand curves. The market parameters are tuned in such a way that a simulation step roughly corresponds to a trading day. Overall, this market model is fairly complete and yields price series with the classical stylized properties found in real price series (i.e., apparent random-walk behavior of prices, fat-tailed distribution of returns and volatility clustering).

First we performed numerous computations for a single market, varying trader composition and tax rate. Levying a tax influences market behavior significantly, even when the rate is low. Price volatility increases consistently with tax rate, but only when chartist traders are present in the market.

These results concur with many empirical findings and provide a measure, using a theoretical model, of the impact of a change in market regulation. However, they can in no way be regarded as conclusive. Trader and/or market models with only slight differences can yield very different results, so further studies are needed to gain a greater insight into market behavior. 
We then studied two related markets, giving each trader the opportunity to choose at each time step the market $\mathrm{s} /$ he prefers to trade in, according to an attraction function. We performed simulations on this market pair with no tax levied, and then taxing one market. First, we observed that, irrespective of trader composition and tax rate, the interplay of markets leads to an increase in price volatility.

Second, we found that, notwithstanding the small transaction tax (typically 0.1-0.5\% of transaction cost) and the simple trader models used, the tax actually heavily impacts market behavior, increasing price volatility and reducing trading volumes. This happens only with trader compositions sensitive to the tax, namely those including chartist traders. Despite the low tax rate, introducing the transaction tax significantly increases price volatility, computed for different time horizons, and reduces trading volumes, though to a lesser extent.

These findings confirm the view that an increase in transaction costs produced by levying the tax, leads to a reduction in market volume and to greater volatility. This behavior appears to be quite robust, in the sense that the effects of the tax are observed for most trader compositions and do not depend on the interplay between two markets, being found even in a single market. The only condition for producing such behavior is the inclusion of speculative traders who follow the trend (or the anti-trend) of prices. In fact, the tax does not seem to influence markets composed simply of random and fundamentalist traders significantly.

These findings seem to contradict the results reported by Westerhoff and Dieci, who found with their model that when a transaction tax is imposed in one market, speculators leave this market, which thus becomes less volatile. However, this contradiction is only apparent. Westerhoff and Dieci's model is much more sophisticated than ours in accounting for informed speculators switching between markets, while in our model the attractivity function is operated by near zero intelligence traders. We found essentially that in our realistic yet simple market model, levying a transaction tax yields a reduction in trading volume and an increase in volatility. A more sophisticated model that better accounts for risk aversion and for the fact that speculators actually leave the taxed market could substantially modify trader composition in the markets, yielding different results.

\section{Acknowledgements}

This work was supported by RAMSES (Research on Agent-based Modeling and Simulation of Economic Systems) research project, sponsored by FIRB re- 
search fund of MIUR, grant number: RBAU01KZ7Z, and by ComplexMarkets E.U. STREP project \#516446, under FP6-2003-NEST-PATH-1

\section{References}

Aliber, Z., Chowdhry, B. and Yan, S.: 2003, Some evidence that a tobin tax on foreign exchange transactions may increase volatility, European Finance Review 7(3), 481-510.

Baker, D.: 2000, Taxing financial speculation: Shifting the tax burden from wages to wagers, Technical report, Center for Economic and Policy Research, Washington, D.C.

Beck, K. and Andres, C.: 2004, Extreme Programming Explained: Embrace Change - Second Edition, Addison-Wesley.

Bottazzi, G., Dosi, G. and Rebesco, I.: 2005, Institutional architectures and behavioral ecologies in the dynamics of financial markets, Journal of Mathematical Economics 41(1-2), 197-228. available at http://ideas.repec.org/a/eee/mateco/v41y2005i1-2p197-228.html.

Ehrenstein, G., Westerhoff, F. and Stauffer, D.: 2005, Tobin tax and market depth, Quantitative Finance 5(2), 213-218.

Felix, D. and Sau, R.: 1996, On the revenue potential and phasing in of the tobin tax, ul Haq/Kaul/Grunberg (Ed.): The Tobin Tax: Coping with Financial Volatility. Oxford University Press pp. 223 - 254.

Friedman, M.: 1953, The Case for Flexible Exchange Rates, Essays in Positive Economics, Chicago University Press, Chicago.

Galati, G., Fornari, F., Mesny, P., Gallardo, P. and Mallo, C.: 2005, Triennial central bank survey: Foreign exchange and derivatives market activity in 2004, Technical report, Bank for International Settlements, Basel.

Habermeier, K. and Kirilenko, A. A.: 2003, Securities transaction taxes and financial markets, in P. Honohan (ed.), Taxation of Financial Intermediation: Theory and Practice for Emerging Economies, World Bank Publications.

Jeffrey A., F.: 1996, How well do foreign exchange markets work: Might a tobin tax help?, ul Haq/Kaul/Grunberg (Ed.): The Tobin Tax: Coping with Financial Volatility, Oxford University Press pp. $41-81$.

Kupiec, P. H.: 1995, A securities transactions tax and capital market efficiency, Contemporary Economic Policy 13, 101-112.

LiCalzi, M. and Pellizzari, P.: 2002, Fundamentalists clashing over the book: A study of order-driven stock markets, Computational Economics 0207001, EconWPA. available at http://ideas.repec.org/p/wpa/wuwpco/0207001.html.

Palley, T.: 1999, Speculation and tobin taxes: Why sand in the wheels can increase economic efficiency, Journal of Economics 69, 113 - 26.

Palley, T. I.: 2003, Debating the Tobin Tax, New Rules for Global Finance Coalition, chapter 2. 
Raberto, M., Cincotti, S., Focardi, S. M. and Marchesi, M.: 2001, Agent-based simulation of a financial market, Physica A 219, 319-327.

Raberto, M., Cincotti, S., Focardi, S. M. and Marchesi, M.: 2003, Traders' long-run wealth in an artificial financial market, Computational Economics 22, 255-272.

Umlauf, S. R.: 1993, Transaction taxes and the behavior of the swedish stock market, Journal of Financial Economics 33, 227-240.

Werner, I. M.: 2003, Comment on 'some evidence that a tobin tax on foreign exchange transactions may increase volatility', Review of Finance 7(3), 511514. available at http://ideas.repec.org/a/kap/eurfin/v7y2003i3p511514.html.

Westerhoff, F.: 2003, Heterogeneous traders and the tobin tax, Journal of Evolutionary Economics 13, 53-70.

Westerhoff, F.: 2004, Multiasset market dynamics, Macroeconomic Dynamics 8(5), 596-616.

Westerhoff, F. and Dieci, R.: 2006, The effectiveness of keynes-tobin transaction taxes when heterogeneous agents can trade in different markets: A behavioral finance approach, Journal of Economic Dynamics and Control 30, 293-322. 